\title{
INFLUENCE OF TEMPERATURE MODES OF PROCESSING CHIA SEED MEAL GEL ON ITS RHEOLOGICAL AND FUNCTIONAL-TECHNOLOGICAL PROPERTIES
}

\author{
Ihor Strashynskiy', Victoria Grechko², Oksana Fursik ${ }^{3}$, Vasyl Pasichnyi ${ }^{4}$, Andrii Marynin ${ }^{5}$ \\ ${ }^{1}$ Department of Technology of Meat and Meat Products, National University of Food Technologies, Kyiv, Ukraine \\ ORCID: https://orcid.org/0000-0002-6591-0414 \\ ${ }^{2}$ Laboratory of Problem Research, National University of Food Technologies, Kyiv, Ukraine \\ ORCID: https://orcid.org/0000-0002-1565-5857 \\ ${ }^{3}$ Department of Technology of Meat and Meat Products, National University of Food Technologies, Kyiv, Ukraine \\ ORCID: https://orcid.org/0000-0002-8816-0388 \\ ${ }^{4}$ Department of Technology of Meat and Meat Products, National University of Food Technologies, Kyiv, Ukraine \\ ORCID: https://orcid.org/0000-0003-0138-5590 \\ ${ }^{5}$ Laboratory of Problem Research, National University of Food Technologies, Kyiv, Ukraine \\ ORCID: https://orcid.org/0000-0001-6692-7472 \\ ${ }^{\square}$ Corresponding author: Andrii Marynin, e-mail: a_marinin@ukr.net
}

ARTICLE INFO

Article history:

Received date 18.11 .2021

Accepted date 21.12.2021

Published date 30.12 .2021

Section:

Food production

D O I

$10.21303 / 2313-8416.2021 .002226$

KEYW ORDS

fiber

chia seed meal

cryoprotective properties

emulsifying properties

shear stress

\section{A B S TRACT}

The object of research. One of the alternatives of naturally occurring structuring agents with great potential in the food industry is the use of chia seeds. The meal obtained from the processing of chia seeds is the object of the above studies.

Investigated problem. The study of changes in the emulsifying and rheological properties of chia seed meal, depending on the temperature treatment regimes, will determine the manifestation of the cryoprotective properties of this additive. This will help to solve the problem of deterioration in the quality of frozen split ends as a result of uncontrolled formation of ice crystals in the structure of the meat product.

Main scientific results. Determination of the effect of heat treatment (heating to $70 \pm 2{ }^{\circ} \mathrm{C}$ and freezing to $-18{ }^{\circ} \mathrm{C}$ in the center) on the emulsifying properties of hydrated systems of chia seed meal showed that the emulsifying ability index increases by $7 \%$ and $16 \%$, and the emulsion stability - by $8.7 \%$ and $18.8 \%$ according to the type of heat treatment. A decrease in emulsifying ability, emulsion stability, effective viscosity and shear stress was found in proportion to an increase in the degree of hydration.

An increase in the indicators of effective viscosity and tangential shear stress as a result of heat treatment of prototypes was noted - by $45.3 \%$ and $46.5 \%$, respectively. Freezing the hydrated dispersion of chia seed meal led to an increase in the ultimate shear stress by an average of $18.45 \%$ compared to the untreated sample, the effective viscosity of the experimental dispersion did not change.

The area of practical use of the research results. It can be used at food industry enterprises to improve the emulsifying and structural properties of products and their enrichment with dietary fiber.

The innovativeness of the proposed solution. The results obtained prove the prospects of using this additive as a stabilizer, emulsifier and cryoprotectant in the technology of frozen meat products.

The area of use of the innovative solution. This will ensure a consistently high quality of finished products and will improve the efficiency of production of a wide range of food products.

(C) The Author(s) 2021. This is an open access article under the Creative Commons CC BY license

\section{Introduction}

1. 1. The object of research

The object of research is meal from chia seeds TM "ZEMLEDAR-INFO" per TU U 10.4137183718-002:2017 "Flour, cereals, flakes, bran and fiber from cereal and oilseed seeds by separating oil from chia seeds". This is ground cake remaining after the press, with a particle size of no more than $0.3-0.6 \mathrm{~mm}$. 


\section{2. Problem description}

There is an increasing trend in the global market to consume foods that are not only nutritionally balanced, but also easy to prepare or ready to eat. The changing tastes and preferences of today's consumers require the industry to transform itself towards finding new natural ingredients for the production and development of products.

Due to the accelerated pace of life, the demand for frozen foods is increasing. The main part of the frozen products market is occupied by cured meat semi-finished products, for which the freezing process is an important technological operation. The use of structure formers, stabilizers and emulsifiers from semi-finished products allows to control and level the functional, chemical and organoleptic properties and avoid defects in the finished product [1]. One of the alternatives of naturally occurring structure-forming agents with great potential in the food industry is the use of chia seeds [2].

Chia seeds (Fig. 1, a) have great potential in the food industry, animal feed, cosmetics and pharmaceuticals, in particular due to their high nutrient content. Chia seeds, which have the ability to form transparent mucus, and thus retain moisture, are 27 times the mass of the seeds themselves [3] (Fig. 1, b).
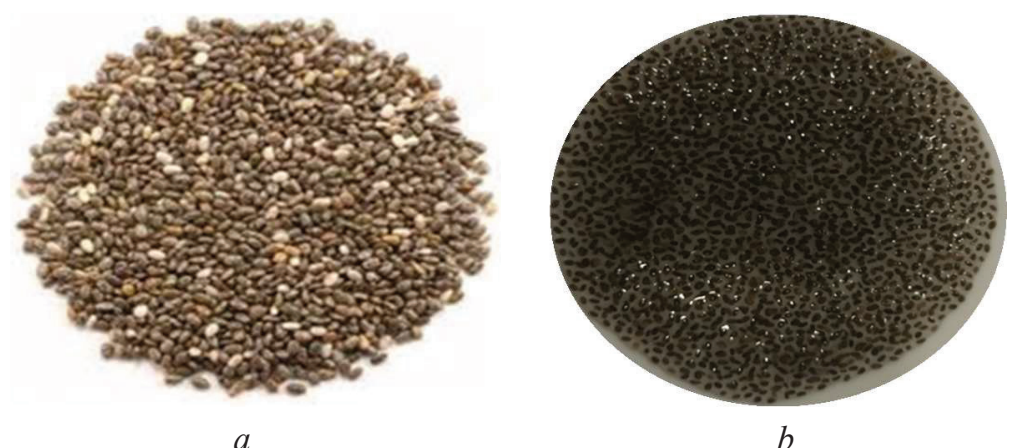

Fig. 1. Chia seeds: $a$-dry; $b$ - formation of a gel from whole seeds

In this context, the use of chia seed dietary fiber can be a useful tool in the development of matrices of structured functional foods.

\section{3. Suggested solution to the problem}

After analyzing the literature, it can be argued that the use of meal and mucus from chia seeds is insufficiently studied and there is little information about the industrial properties that could provide useful components (thickeners, stabilizers, emulsifiers). It is known that mucus from chia seeds and chia seed meal were examined for rheological parameters and compared with guar gum and gelatin [4].

Other studies $[5,6]$ focused on the study of the physicochemical properties and the ability to glue, spread chia flour and mucus. The study of the functional properties made it possible to establish that chia absorbs a significant amount of water, which affects the viscosity of the suspensions formed by the chia flour. Determination of the rheological properties of chia flour showed that the relative viscosity of the systems is mainly determined by the content of fibers and proteins, and also depends on the concentration and temperature, in turn, the viscosity of mucus from chia seeds does not depend on temperature [7].

In the materials of the article [8], studies of the dependence of functional properties on the type of additive from chia seeds (meal or fibrous fraction - fiber) are given. The results showed that all samples exhibit high antioxidant activity due to the high content of phenolic compounds and tocopherol. The meal and fiber obtained as a result of solvent extraction showed higher absorption of fat molecules, organic compounds, emulsifying activity and made it possible to obtain more stable emulsions in comparison with samples extracted by pressing. Along with this, the highest moisture-absorbing and adsorbing capacities were noted for fiber from chia seeds [8].

In the last decade, significant efforts have been directed towards finding sources and combinations of hydrocolloids in order to maximize their effectiveness and eliminate a number of structural and functional problems in the food industry. However, there is still room in the market for 
new sources of plant hydrocolloids to meet the demand for ingredients with specific functionality in food and chemical systems.

The aim of this research is to study the rheological properties of chia seed meal, its ability to interact with water and fat molecules in two-phase systems, and to establish the effect of temperature and additive concentration on the change in these properties to determine potential uses in semi-finished products.

\section{Materials and Methods}

At the Department of Meat and Meat Products Technology and the Problem Research Laboratory of the National University of Food Technologies (Kyiv, Ukraine), studies of hydrated samples of chia seed meal were carried out in different ratios (meal: water) - 1:10, 1:15, 1:20, 1:25. Chia seed meal was chosen under the ZEMLEDAR trademark (according to TU U 10.41-37183718-002:2017 "Flour, cereals, flakes, bran and fiber from cereal and oilseed seeds by separating oil from seeds). The selected sample of chia seed meal contains $18 \mathrm{~g}$ of protein, $20 \mathrm{~g}$ of carbohydrates. For the research, experimental suspensions were prepared by hydration of the meal with water at room temperature $\left(10-15^{\circ} \mathrm{C}\right)$. Studies of rheological and emulsifying properties were carried out for samples immediately after preparation; after heating in a water bath to $70 \pm 2{ }^{\circ} \mathrm{C}$ in the center and subsequent cooling to a temperature of $12 \pm 2{ }^{\circ} \mathrm{C}$; after keeping in a frozen state for 1 month (temperature $-18{ }^{\circ} \mathrm{C}$ ) and subsequent defrosting at room temperature until a temperature in the thickness of $0-2{ }^{\circ} \mathrm{C}$ is reached. To study the rheological properties, determine the indices of shear stress and effective viscosity. The tangential shear stress and effective viscosity were determined using a "Reotest-2" rotational viscometer. The order of the analysis: a suitable measuring cylinder is preselected, guided by the tabular values [9]. The test sample is placed in a corresponding glass with a geometrically closed bottom and coaxially to the rotor using a screw clamp is fixed on the measuring unit. The device is connected to the mains, the required rotor speed is set, these indicators of the viscometer are recorded, and the calculation is made. The value of the shear stress, measured at different speeds of rotation of the rotor of the selected measuring head in accordance with the rigidity of the torsion bar, is calculated by the formula:

$$
\theta=Z \cdot \alpha
$$

where $Z$ - rotor constant, $\alpha$-ratiometer readings.

To construct a rheogram - the yield curve $N_{L}(\theta), 12$ experimental points are sufficient in the range from the minimum to the maximum rotor speed.

The effective viscosity at each rotor speed is calculated by the formula:

$$
\mathrm{H}_{e f}=k \cdot \theta / N_{L},
$$

where $k$-constant of the measuring head; $N_{L}$-yield curve; $\theta$ - shear stress.

To establish the ability of the resulting gels to absorb and retain the fat phase in their structure, the emulsifying properties, namely the emulsifying ability and stability of the emulsion, were investigated.

The indicators of the stability of the emulsion and the emulsifying ability were determined by measuring the amount of oil separated during the centrifugation of the preliminarily prepared emulsion after heating at a temperature of $80{ }^{\circ} \mathrm{C}$ and without heating, respectively [10].

The absolute measurement error was determined using the Student's test, the confidence interval $p=0.95$, the number of repetitions in the definitions 3-4, the number of parallel samples of the prototypes - 3. Statistical analysis was performed using Microsoft Excel 2007.

\section{Results}

This type of additive (chia seed meal) in the composition of meat and meat-intensive split ends is used as a cryoprotectant. In this regard, it is advisable to establish its effect on the stability of the meat emulsion.

Studies of the stability of the water-fat system with hydrated chia seed meal have established that the emulsifying ability and stability of the emulsion of research systems decrease with an increase in the degree of hydration. At a degree of hydration of $1: 10$, the emulsifying capacity is $42 \%$, and the stability of the emulsion is $34 \%$. With an increase in the amount of the water fraction, these 
indicators decrease by $9.5 \%, 19 \%, 23.8 \%$ and $8.8 \%, 14.7 \%, 23.5 \%$, respectively. The data obtained are related to the protein and carbohydrate content (namely, fiber) in the composition of the chia seed meal. This coincides with a study [11], which found that seed fractions with a high content of insoluble dietary fiber more efficiently absorb organic molecules, as is the case with wheat and corn husks. Accordingly, these data allow to state about the possibility of using this additive as an emulsifying agent in the composition of meat products with a long shelf life.

The processing of prototypes by heating and freezing indicates an increase in the number of active groups for absorption and the content of fat molecules in the composition of hydrated samples. The studied indicators of the emulsifying ability and stability of the emulsion increase by $7 \%$ and $8.7 \%$ and $16 \%$ and $18.8 \%$ in comparison with the hydrated samples without treatment.

To establish the structure-forming characteristics of chia seed meal, a study was carried out depending on the effective viscosity and shear displacement stress (Fig. 2-5) of hydrated samples on the concentration of chia seed meal in their composition.

The analysis of the results obtained on the study of the effective viscosity indicator confirms similar studies by other scientists $[8,12]$, who observed a decrease in this indicator with a decrease in the concentration of particulate matter and an increase in the dispersion medium in the composition of hydrated samples. The chia seed meal test sample contained a dispersion of hydrated microgel particles. By comparing the data obtained, it was found that the effective viscosity with an increase in the degree of hydration decreases by $44.3 \%, 75 \%, 87.6 \%$ in comparison with the sample hydrated in a ratio of 1:10.

Heating the prototypes to a temperature in the center of $70 \pm 2{ }^{\circ} \mathrm{C}$ leads to a maximum increase in the viscosity of the formed dispersions, which indicates the thermal stability of the proposed additive, the ability to form a microgel structure in the finished product and retain moisture during heat treatment of semi-finished products.

By studying the effect of low temperatures on the viscosity of the resulting system, the presence of cryoprotective properties for the proposed additive was established. This is due to insignificant fluctuations in the effective viscosity index for experimental systems at all degrees of hydration.

One of the rheological characteristics of dispersed systems, along with the effective viscosity index, is the shear stress, which allows one to characterize the experimental systems in terms of the strength of the thixotropy of the structure and the ability to resist the applied force, that is, characterizes the strength of the dispersion [13]. The obtained results of studying the influence of the degree of hydration and temperature regimes of treatment on the index of the shear stress of dispersions from chia seed meal are shown in Fig. 2-5.

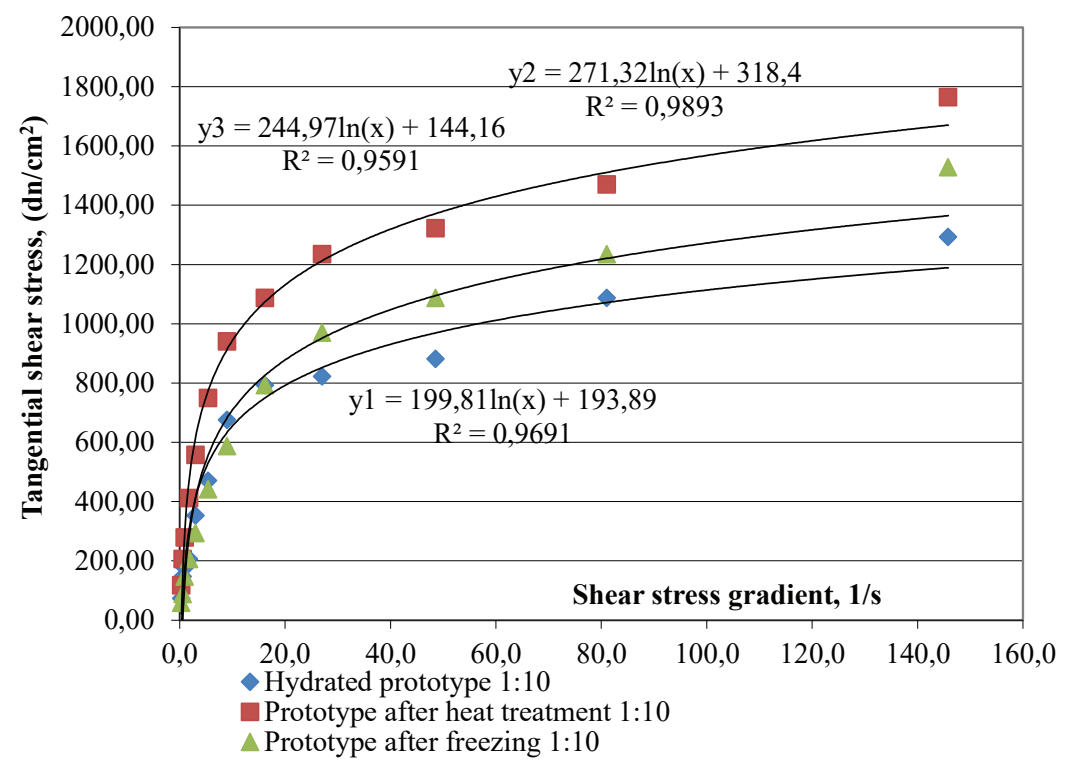

Fig. 2. Dependence of the tangential shear stress of the gel from the chia seed meal on the shear stress gradient (degree of hydration 1:10) 


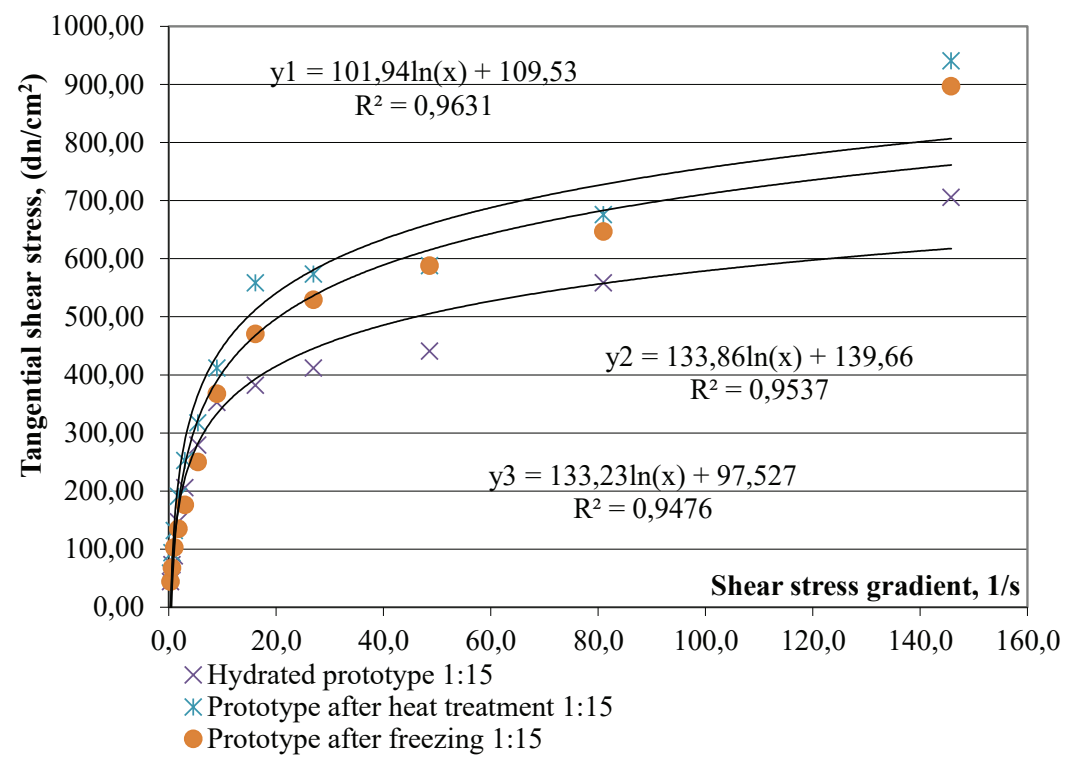

Fig. 3. Dependence of the tangential shear stress of the gel from the chia seed meal on the shear stress gradient (degree of hydration 1:15)

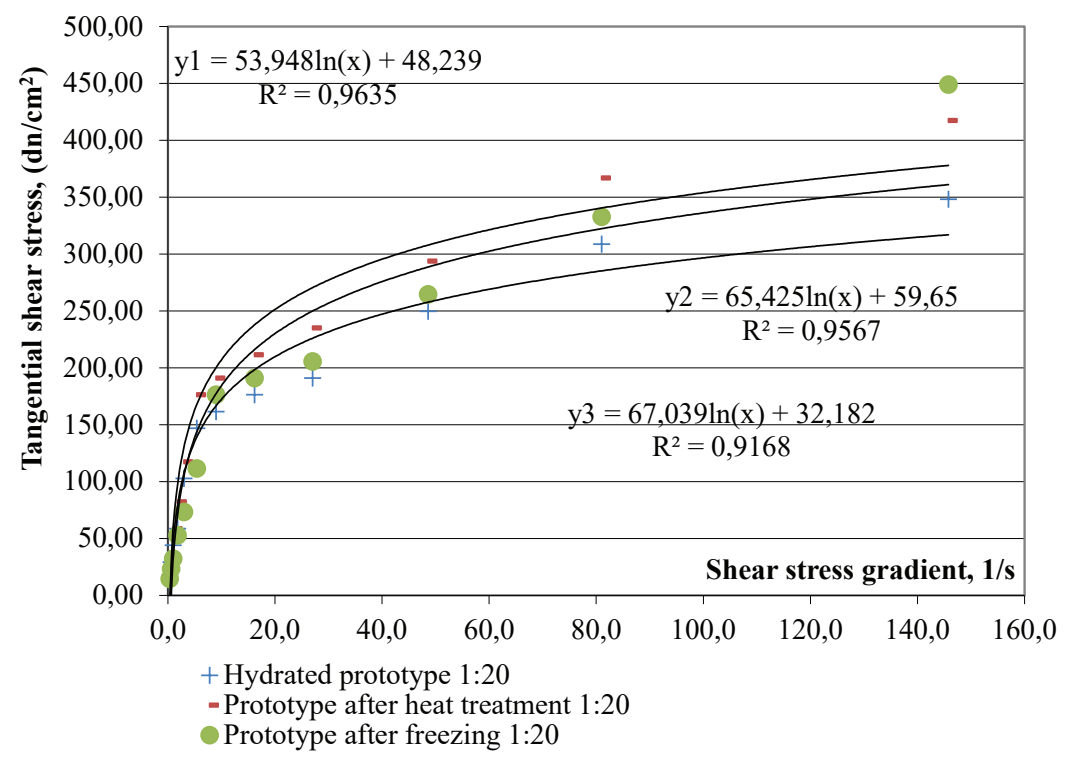

Fig. 4. Dependence of the tangential shear stress of the gel from the chia seed meal on the shear stress gradient (degree of hydration 1:20)

Similarly to the effective viscosity indicators, a decrease in the shear stress indicator is observed in proportion to an increase in the degree of hydration of the test specimens.

The study of the index of the tangential shear stress made it possible to confirm the positive effect of changing the temperature regimes of processing. The data obtained established an increase in the ability to resist the applied force due to exposure to low temperatures (freezing) at a degree of hydration of $1: 10$ by $6.5 \%, 1: 15$ by $15.85 \%, 1: 20$ by $9.1 \%$ and $1: 25$ - by $42.3 \%$ compared to prototypes without processing. The maximum increase in the shear stress index is characterized after heat treatment at all degrees of hydration (on average by $46.5 \%$ ) and corresponds to the data obtained in the study of effective viscosity indicators. The shear stress index increases after heat treatment and thawing/freezing processes, which has a positive effect on the properties of the chia seed gel. The equations and approximation coefficients shown in Fig. 2-5 indicate the reliability of the data obtained $(p<0.05)$.

Similarly to the study of the rheological properties, a decrease in the strength of the formed gel with an increase in the degree of hydration was observed. Having analyzed the effect of chang- 
ing the temperature regimes of processing on the stability of gel systems, it is advisable to note the formation of a more durable structure as a result of heating the prototypes. Exposure to low temperatures (freezing) made it possible to improve the structure of the formed gel at all degrees of hydration; however, the prototypes were inferior to the formed gels after heat treatment.

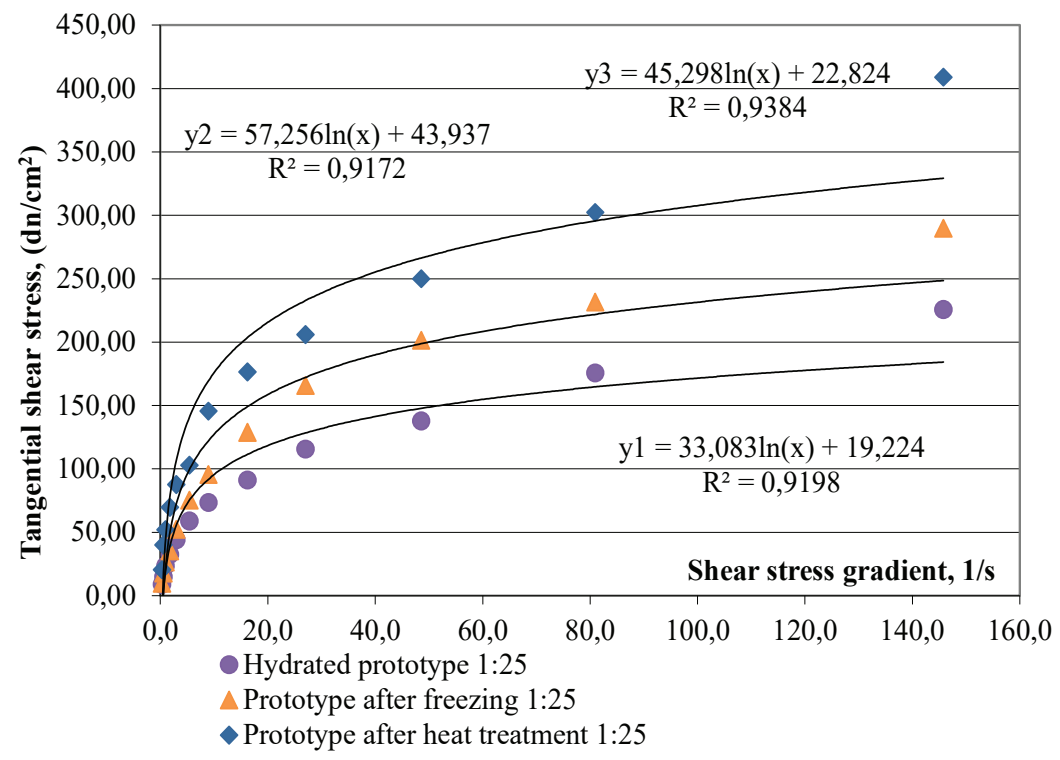

Fig. 5. Dependence of the tangential shear stress of the gel from the chia seed meal on the shear stress gradient (degree of hydration 1:25)

The study of the emulsifying and rheological properties of the Chia seed meal will allow predicting the effect of this additive on the stability of meat emulsions and rationally establishing the amount of its introduction. Depending on the production conditions and capacities, different batches of chia seed meal may differ in fractional composition, which will affect the properties and quality of the final product. In this regard, the use of this additive requires constant analysis of its properties and determination of the rational amount of application. To fully characterize this additive, it is advisable to establish its behavior in the composition of meat products and to determine the ability to stabilize the formed structure, which is the next stage of research.

\section{Conclusions}

The expediency of using chia seeds as a stabilizer, structurant and cryoprotectant in the meat industry is substantiated. A high content of fiber and protein in seeds is noticed, which provides high functional properties of this supplement. Chia seed meal is selected for research in order to rationalize the use of resources.

The stability of hydrated systems based on chia meal prior to exposure to temperature is noticed. It is found that the indicators of emulsifying ability and stability of the emulsion improved by $16 \%$ and $18.8 \%$, respectively, after freezing processes. This confirms the ability of dietary fiber to influence the freezing process and, in the process, reduce the size of fat molecules in the emulsion, stabilizing it.

The study of the rheological properties indicates the detection of non-Newtonian behavior of the system. Viscosity shows a direct proportion to concentration and decreases as the displacement rate increases, resulting in fluidization of the system upon displacement. As for the dependence on concentration, it was found that in the region of higher concentration, the viscoelastic and solid-like behavior of the suspension depends on dynamic changes in the volume of the particle phase.

By studying the effect of various modes of temperature treatment, a modification of the effective viscosity and shear stress of the test specimens is established, which consisted in increasing this property and, accordingly, indicates the thickening of the experimental system and the formation of more stable and strong bonds between the molecules of the chia seed meal. The effect of temperature increases the viscosity characteristics, which is more observed in solutions with a 
higher concentration, which suggests that this system will improve the viscosity characteristics both at the production stage and in the finished product. Heating and freezing increase the shear stress index by an average of $46.5 \%$ and $18.5 \%$, respectively.

The use of these dispersions in food technology has many advantages in providing varying degrees and mechanisms for stabilizing food systems.

\section{References}

[1] Younis, K., Yousuf, O., Qadri, O. S., Jahan, K., Osama, K., Islam, R. U. (2022). Incorporation of soluble dietary fiber in comminuted meat products: Special emphasis on changes in textural properties. Bioactive Carbohydrates and Dietary Fibre, 27, 100288. doi: http://doi.org/10.1016/j.bcdf.2021.100288

[2] Muñoz, L. A., Cobos, A., Diaz, O., Aguilera, J. M. (2013). Chia Seed (Salvia hispanica): An Ancient Grain and a New Functional Food. Food Reviews International, 29 (4), 394-408. doi: http://oi.org/10.1080/87559129.2013.818014

[3] Hernandez, L. M. (2012). Mucilage from chia seeds (Salvia hispanica): Microstructure, physico-chemical characterization and applications in food industry. Pontificia Universidad Catylicade Chile, 146.

[4] Coorey, R., Tjoe, A., Jayasena, V. (2014). Gelling Properties of Chia Seed and Flour. Journal of Food Science, 79 (5), E859E866. doi: http://doi.org/10.1111/1750-3841.12444

[5] Otondi, E. A., Nduko, J. M., Omwamba, M. (2020). Physico-chemical properties of extruded cassava-chia seed instant flour. Journal of Agriculture and Food Research, 2, 100058. doi: http://doi.org/10.1016/j.jafr.2020.100058

[6] Chiang, J. H., Ong, D. S. M., Ng, F. S. K., Hua, X. Y., Tay, W. L. W., Henry, C. J. (2021). Application of chia (Salvia hispanica) mucilage as an ingredient replacer in foods. Trends in Food Science \& Technology, 115, 105-116. doi: http://doi.org/10.1016/j. tifs.2021.06.039

[7] García-Salcedo, Á. J., Torres-Vargas, O. L., del Real, A., Contreras-Jiménez, B., Rodriguez-Garcia, M. E. (2018). Pasting, viscoelastic, and physicochemical properties of chia ( Salvia hispanica L. ) flour and mucilage. Food Structure, 16, 59-66. doi: http://doi.org/10.1016/j.foostr.2018.03.004

[8] Capitani, M. I., Spotorno, V., Nolasco, S. M., Tomás, M. C. (2012). Physicochemical and functional characterization of by-products from chia (Salvia hispanica L.) seeds of Argentina. LWT - Food Science and Technology, 45 (1), 94-102. doi: http://doi. org/10.1016/j.lwt.2011.07.012

[9] Machikhin, Yu. A., Gorbatov, A. S., Maksimov, A. S. et. al. (1990). Reologiya pischevogo syrya i produktov. Moscow: Agropromizdat, 271.

[10] Pasichnyi, V. M., Strashynskyi, I. M., Fursik, O. P. (2015). Investigation of the emulsions based on functional food compositions containing protein. Technology Audit and Production Reserves, 3 (3 (23)), 51-55. doi: http://doi.org/10.15587/23128372.2015.44177

[11] Pintado, T., Ruiz Capillas, C., Herrero, A. M. (2019). New Lipid Materials Based on Chia Emulsion Gels: Application in Meat Products. Biomedical Journal of Scientific \& Technical Research, 18 (1). doi: http://doi.org/10.26717/bjstr.2019.18.003088

[12] Timilsena, Y. P., Adhikari, R., Kasapis, S., Adhikari, B. (2015). Rheological and microstructural properties of the chia seed polysaccharide. International Journal of Biological Macromolecules, 81, 991-999. doi: http://doi.org/10.1016/j.ijbiomac.2015.09.040

[13] Pasichnyi, V. M., Yastreba, Yu. A. (2013). Doslidzhennia strukturno-mekhanichnykh vlastyvostei heliv alhinativ dlia vyrobnytstva miasnykh i miasomistkykh produktiv. Naukovyi visnyk LNUVMBT im. S. Z. Hzhytskoho, 15 (1 (3)), 125-129. 